\title{
Design of a Fast Temporary Fastener with the Labor-Saving and Reversible Ability
}

\author{
Wei Tang ${ }^{1} \mathbb{B}$, Xincheng $\mathrm{Xie}^{2, *}$, Yukang $\mathrm{Ye}^{1}$ and Weiwei $\mathrm{Qu}{ }^{3}$ \\ 1 School of Intelligent Engineering, Shaoguan University, Shaoguan 512023, China; \\ tangweijmsdx@163.com (W.T.); yykdeyouxiango@163.com (Y.Y.) \\ 2 School of Electromechanical Engineering, Guangdong University of Technology (GDUT), \\ Guangzhou 510006, China \\ 3 College of Mechanical Engineering, Zhejiang University, Hangzhou 310027, China; qwwwwl@zju.edu.cn \\ * Correspondence: rehiest@163.com
}

check for

updates

Citation: Tang, W.; Xie, X.; Ye, Y.; Qu, W. Design of a Fast Temporary Fastener with the Labor-Saving and Reversible Ability. Coatings 2021, 11, 1101. https://doi.org/10.3390/ coatings11091101

Academic Editor: Vasileios Koutsos

Received: 28 July 2021

Accepted: 9 September 2021

Published: 12 September 2021

Publisher's Note: MDPI stays neutral with regard to jurisdictional claims in published maps and institutional affiliations.

Copyright: (c) 2021 by the authors. Licensee MDPI, Basel, Switzerland. This article is an open access article distributed under the terms and conditions of the Creative Commons Attribution (CC BY) license (https:// creativecommons.org/licenses/by/ $4.0 /)$.

\begin{abstract}
Aircraft panel assembly mainly includes the pre-joining process and the riveting process. In addition, the traditional pre-joining process is mainly executed by bolts, which has problems such as the large tightening torque, inconvenient bilateral tightening, heavy workload, and inconvenient loading and unloading. To solve the above-mentioned problems, a research of new temporary fastener is performed deeply from three levels of quick installation, labor-saving, and reversible ability. This involves (a) employing the lever mechanism and the rapid expansion anchor to implement the rapid clamping and disassembly of working processes by labor-saving; (b) integrating the adjusting spring to overcome the tolerances of parts; and (c) building up the space-cross slide rails to provide the axial clamping forces and the reversible forces. The application of designed fasteners was employed into the production of aircraft panel, and the error between theoretical and experimental values was less than $10 \%$. Besides this, the result showed the good effect in panel clamping and the reliable processes of loading and unloading installation, and will greatly reduce the complexity of pre-joining process, the difficulty of installation, and the comprehensive cost.
\end{abstract}

Keywords: labor-saving; reversible; quick installation and disassembly; lever principle

\section{Introduction}

Aircraft panel assembly mainly includes two stages: the pre-joining process and the riveting process [1]. Panels usually require a certain number of temporary fasteners to make the pre-joining before riveting, to reduce the initial clearance of assembly, and to fix the relative position of each part. The traditional pre-joining process is mainly fastened by bolts, and this kind of fasteners adopts the method of bilateral fastening when clamping [2]. Namely, bolts and nuts need to be installed on both sides of the panel. The length and width of aircraft panel being generally more than $1000 \mathrm{~mm}$ will lead to the low installation efficiency, the large labor intensity, and the poor man-machine friendliness.

In a society with highly developed technology, the industrial field put forward the concept of "intelligent manufacturing", and the development of industrial design will develop towards automation, intelligence, and so on [3-6]. As an important part in the field of mechanical design, fasteners are used to ensure the normal assembly and processing of parts. Therefore, higher requirements will be put forward for its efficiency and performance.

In the field of aviation assembly, temporary fasteners play a key role in improving the initial conditions of drilling and riveting in the next step. The research on temporary fasteners has important academic value and engineering application value [7].

In the aspect of panel pre-joining processing, Yang Di and Liu Gang et al. [8-11] focused on the problems of excessive number and inappropriate position of pre-joining holes, established a model on deformation of pre-joining, and proposed a method of 
equivalent clearances calculation to realize the rapid prediction of residual gap after prejoining. To improve the efficiency of pre-joining process, Zhou Shuyang et al. [12] improved the simulated annealing algorithm, applied it to the layout of pre-joining holes, and saved a lot of work time. Liu Xia et al. [13] studied the influence of clamping force of fasteners on the deformation of aircraft panel assembly, established deformation analysis method of aircraft panel based on the positioning process of parts, and proposed a more accurate and reliable prediction of part deformation. The above literatures have studied the aspects of pre-joining deformation and efficiency. However, they did not research the innovative design of temporary fasteners for pre-joining.

In terms of fasteners, Xiaodong Huang and Quan Wang [14] theoretically designed a pre-joining fastener model and an end-effector for automatic installation of aircraft assembly, which used the expansion bolts principle, a screw transmission structure, and an automatic installation system to achieve fastening connection. However, in this design, there are problems, such as it being expensive, complicated, time-consuming, and laborconsuming. The experimental research was also not carried out. Cheng Yalong et al. [15] proposed a fast assembly method for fasteners with feature recognition, but this method still uses bolts for bilateral fastening, and does not optimize the installation efficiency of the fasteners themselves. Camacho Javier et al. [16] designed an online detection method for blind fasteners that were installed incorrectly based on the sensor signal during the installation process. The results show that the method can identify the torque diagrams, whether the installation process is normal or not. The system is an automatic and accurate detection system, and has the ability to automatically recognize and classify installation process. Wilson et al. [17] designed a surface acoustic strain sensor to apply into the fault detection of aircraft fasteners, which could successfully detect the failure of a single fastener, but there was no structural design of fastener related to this sensor. In order to improve the connection strength and study the optimization of connection structure, Li Yan et al. [18] analyzed the repair of connection round hole damage based on the elastic-plastic finite element method, and also displayed the connection load of all rivets under the three different patch shapes. These results have demonstrated that the strength of aircraft skin after riveting can be significantly improved by using the circular patch structure, compared with the rectangular patch and the rounded rectangular patch, under the same materials, riveting parameters, and process equipment. Nevertheless, the strength problem after pre-joining for them was not studied.

In order to solve the problems of high cost and low precision for the pre-joining process of a traditional aircraft panel, this paper designs a temporary fastener for pre-joining with single-side installation as well as labor-saving and reversible ability, combining the lever principle, the anchor expansion mechanism, the adjusting spring, and the space-cross slide rails.

\section{Innovative Design of Temporary Fastener}

\subsection{Functional and Structural Innovative Design}

To achieve the requirement of the unilateral quick installation and disassembly in the pre-joining process of aircraft panels, the following functions and their innovative structures are designed in Table 1.

Table 1. Functions and corresponding innovative structures.

\begin{tabular}{cc}
\hline Functions & Corresponding Innovative Structure \\
\hline Labor saving & $\begin{array}{c}\text { Based on the lever principle, a new lever mechanism } \\
\text { with a movable fulcrum is designed to achieve the } \\
\text { purpose of labor saving in the working process. }\end{array}$ \\
Reversible ability & $\begin{array}{c}\text { A expansion anchor mechanism with strong elastic } \\
\text { materials is designed for this function, which could } \\
\text { be recovered to the original shape after the } \\
\text { clamping process. }\end{array}$ \\
\hline
\end{tabular}


Table 1. Cont.

\begin{tabular}{cc}
\hline Functions & $\begin{array}{c}\text { Corresponding Innovative Structure } \\
\text { Consideration of component tolerances }\end{array}$ \\
$\begin{array}{c}\text { Generally in the pre-joining process of aircraft } \\
\text { panels, there is a tolerance for the thickness of } \\
\text { workpiece. To solve this problem, an adjustment } \\
\text { mechanism is designed by adjusting the } \\
\text { pre-compression of the spring to overcome the } \\
\text { tolerance in the actual work. }\end{array}$ \\
$\begin{array}{c}\text { Most of the existing fastening methods are bilateral } \\
\text { fastening with bolt connections, and the production } \\
\text { efficiency is not high [19]. In order to solve this } \\
\text { problem, an anchor-expanding mechanism is } \\
\text { designed; that is, employ the expansion anchors and } \\
\text { the moving expansion shafts to cooperate to achieve } \\
\text { unilateral fastening. }\end{array}$ \\
\hline
\end{tabular}

And their specific structure is illustrated in Figure 1.

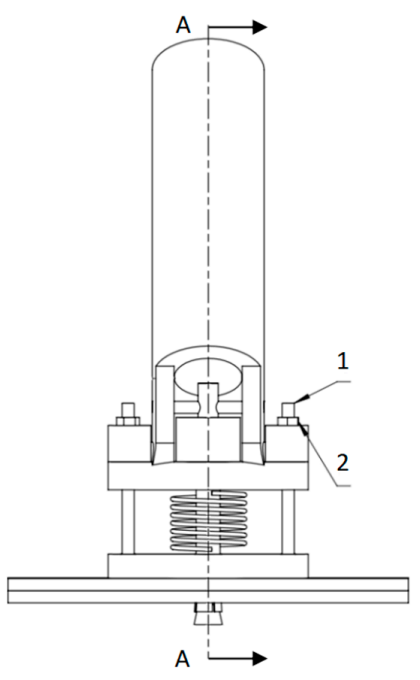

A

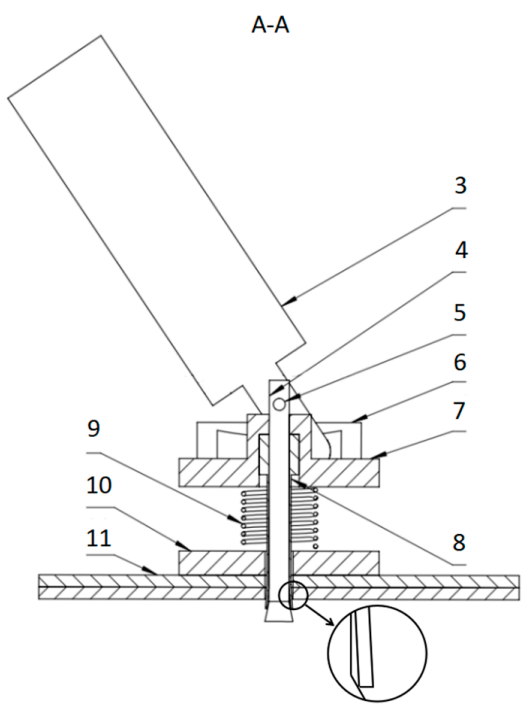

(a)

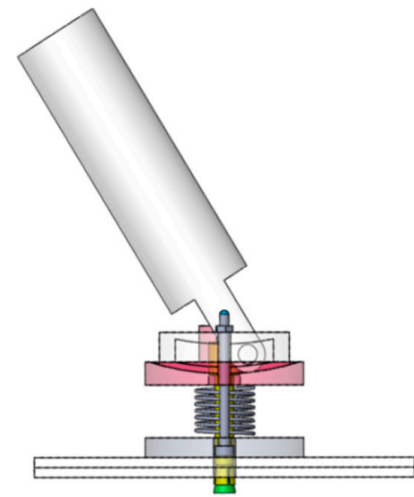

(b)

Figure 1. (a) Two-dimensional diagram of new temporary fasteners. 1-Adjusting bolt; 2-Adjusting nut; 3-Leverage; 4-Expansion shaft; 5-Pin shaft; 6-Chute cover; 7-Chute table; 8-Expansion anchor; 9-Spring; 10-Adjustment board; 11-Workpiece; (b) Three-dimensional diagram of temporary fasteners. 
Assembly process of the temporary fastener is as follows. First, the expansion anchor and the chute table are connected by thread, and then the expansion anchor is inserted into the stepped hole of the chute table. Secondly, a matching relationship is made between the expansion shaft and the expansion anchor, i.e., a transition fit, and the expansion shaft is inserted from the lower end of the expansion anchor into the corresponding position, so that the expansion shaft, expansion anchor, and the chute table complete the connection process. Then, the pin shaft is passed through the holes of the expansion shaft and the lever, and the connection process is completed. In this phase, the expansion shaft, the expansion anchor, the chute table, and the lever are connected. Afterwards, spring and the adjusting plate from the bottom one by one are installed, the spring between the adjustment plate and the chute table is clamped, and the bolts inserted into the adjusting plate and the chute table are adjusted in turn. Finally, the two chute table are covered, and the nuts of the two adjusting bolts are screwed on to complete the assembly of the whole device.

\subsection{Apply Method of Temporary Fasteners on Aircraft Panel}

\subsubsection{Preparation Action}

The work-pieces are placed with holes on top of each other, then the expansion shaft and expansion anchor are passed through the hole to complete the preparation action, as shown in Figure 2.

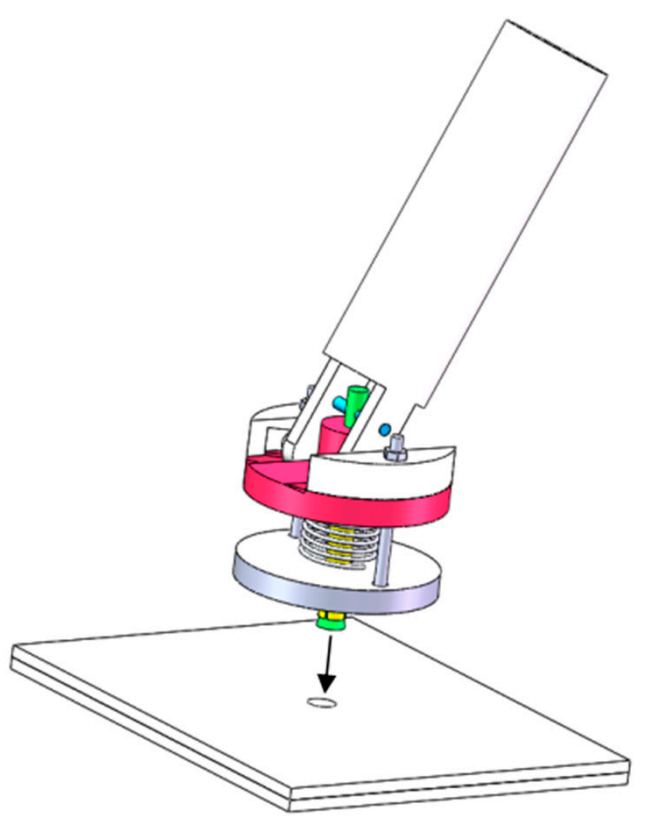

Figure 2. Preliminary installation process.

\subsubsection{Clamping Process}

The whole clamping process is divided into two stages.

1. The first stage is the upward expansion stage. In this stage, the lever is rotated to drive the expanding shaft to lift up. The lifting resistance caused by the expansion of the expansion anchor is small, and it is not enough to overcome the resistance of the spring to compress it, so no clamping force is generated between the two workpieces.

2. The second stage is the clamping stage. In the first stage, the expansion anchor is stretched by the expansion shaft until it contacts the workpiece. Therefore, in this stage, the lever mechanism continues to rotate, and the force is transmitted to the chute table through the lateral convex platform of the short part of the lever. Next, the pin shaft is employed as the fulcrum to press down the chute table, so that the spring between the chute table and the adjusting plate is compressed to produce elastic force. Then, the adjust plate cooperates with the expanded anchor to produce clamping 
force. Finally, the clamping force is the largest at the time when the lever is in the vertical position, and the fastening action is completed. It can be seen from the above that the device has the advantages of simple operation and reliable structure.

\subsubsection{Disassembly Process}

The disassembly process is also divided into two stages. In the first stage, the lever is rotated slightly and the spring gradually recovers from the compressed state to the pre-compressed state. Consequently, the contact point of the chute table cover and the short convex head is used as the fulcrum to press down the shaft, and the expansion anchor recovers from the expanded state and completes the disassembly process.

\section{Relationship Analysis of Temporary Fastener}

\subsection{Analysis of Geometric Relationship}

Assume that $L_{s}$ in Figure 3 represents the distance from the middle hole of the lever to the bottom. Take $L_{s}$ as a stage flag, the whole working process is divided into the upward expansion stage and the downward clamping stage. Because the upward expansion stage does not produce clamping force, the analysis of geometric relations is the beginning of the downward clamping stage:

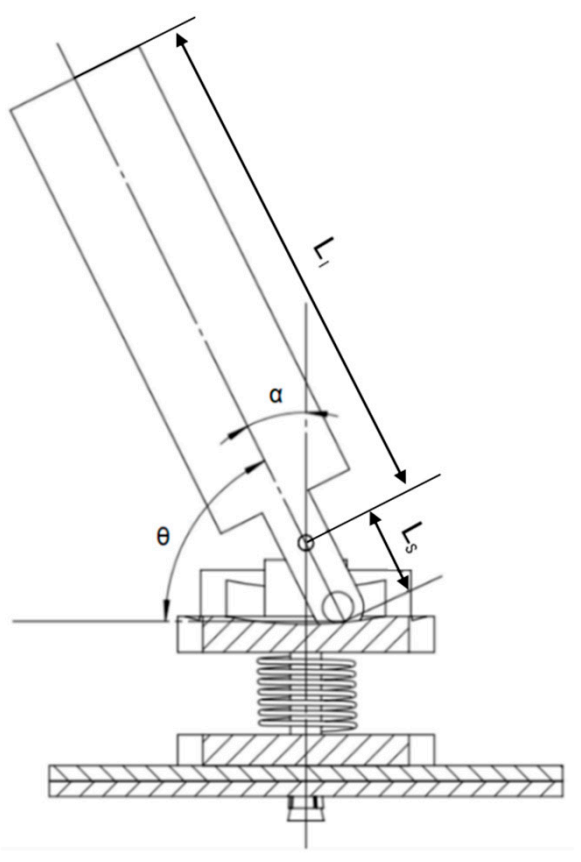

(a)

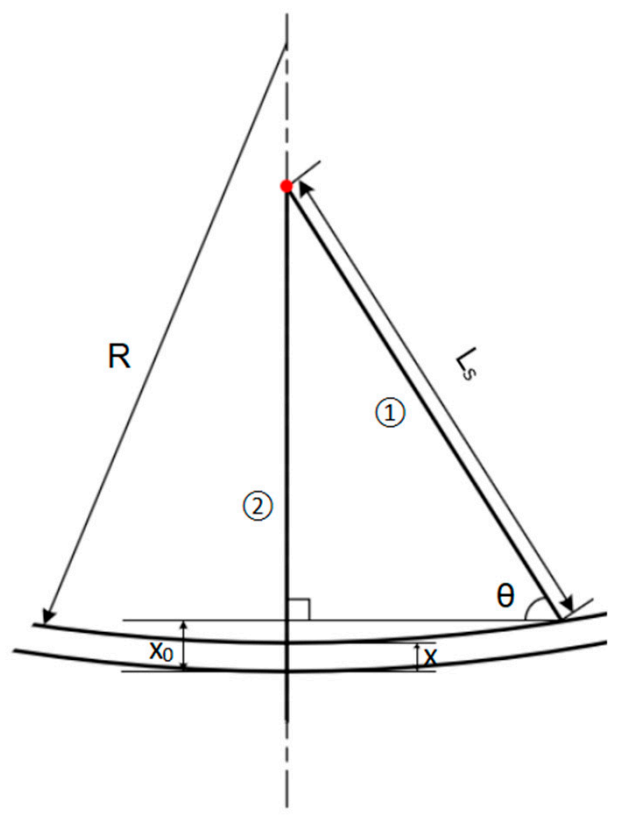

(b)

Figure 3. (a) Geometric relationship of temporary fasteners. (b) Geometric relationship analysis.

At the clamping stage, the bottom of the lever moves from position (1) to position (2), making circular motion with the fulcrum as the sports center. The angle between the horizontal line and the center line of the lever at the beginning of the clamping stage is $\theta$, and $\alpha$ is the angle between the center line of the lever and the vertical line.

If $\alpha$ is too small, it may cause the lever to sway during processing and tightening failure. If $\alpha$ is too large, the tightening process will be inconvenient.

$\theta$ and $\alpha$ have the following relationship:

$$
\theta=\frac{\pi}{2}-\alpha
$$

$\mathrm{R}$ represents the radius of the rail arc of the chute table, and $x_{0}$ represents the theoretical compressed amount of the spring, $x$ represents the actual compressed amount of the spring. 
Affected by the arc of the chute, the actual compressed amount will be slightly smaller than the theoretical compressed amount.

In the clamping stage, the lever uses the pin as a fulcrum to compress the spring, and the ideal compression amount of the spring in this process is $x_{0}$.

$x_{0}$ can be calculated:

$$
x_{0}=L_{\mathrm{s}} \cdot(1-\cos \theta)
$$

$x$ can be calculated:

$$
x=L_{\mathrm{S}} \cdot(1-\cos \theta)-R+\sqrt{R^{2}-\left(L_{S} \cdot \sin \alpha\right)^{2}}
$$

The relation between $x_{0}$ and $x$ is:

$$
x_{0}-x=R-\sqrt{R^{2}-\left(L_{\mathrm{s}} \cdot \sin \alpha\right)^{2}} x
$$

In order to make a reliable fastening, the angle $\alpha$ should not be too small, i.e., about $45^{\circ}$. To make the tightening process smooth, $\mathrm{R}$ should take a larger value. Therefore, in the tightening process, the influence of the rail arc on the compression of the spring can be ignored, and the difference between $x_{0}$ and $x$ is negligible. Approximately replace $x$ with $x_{0}$ for calculation.

$\Delta h$ represents the tolerance of the thickness of the two plates during processing, and $F_{j}$ represents the clamping force, and $k$ represents the elastic coefficient of the spring

As obtained from Hooke's law, when the compression amount of the spring is $x_{0}, F_{j}$ can be calculated:

$$
F_{j}=k \cdot\left(x_{0}+\Delta h\right)
$$

\section{Theorem 1. Hooke's law.}

$\Delta h$ is positive when the thickness of the plate is greater than the standard value; in this case, the adjusting nut should be tightened before clamping the plate, so that the adjusting spring can compress to overcome the positive tolerance. Since the adjustment spring increases the amount of pre-compression, the actual clamping force is slightly bigger than calculated by $k \cdot \Delta h$.

$\Delta h$ takes a negative value when the thickness of the plate is less than the standard value; in this case, in order to compensate the negative tolerance, it is necessary to loosen the adjusting nut before clamping the plate. Since the adjustment spring decreases the amount of pre-compression, the actual clamping force is slightly less than calculated by $k \cdot \Delta h$.

\subsection{Analysis of Mechanical Relationship}

1. The weight of the lever has limited influence on the whole process, so that it is negligible. The follows analyze the force on the lever.

Figures $a$ and $b$ in Figure 4 respectively show the force on the lever during the clamping process and the balance state.

$F_{n}$ - User's tightening force;

$F_{0}$ - The counterforce on the lever from the chute table;

$F_{j}$ — The counterforce on the lever from the pin shaft. 


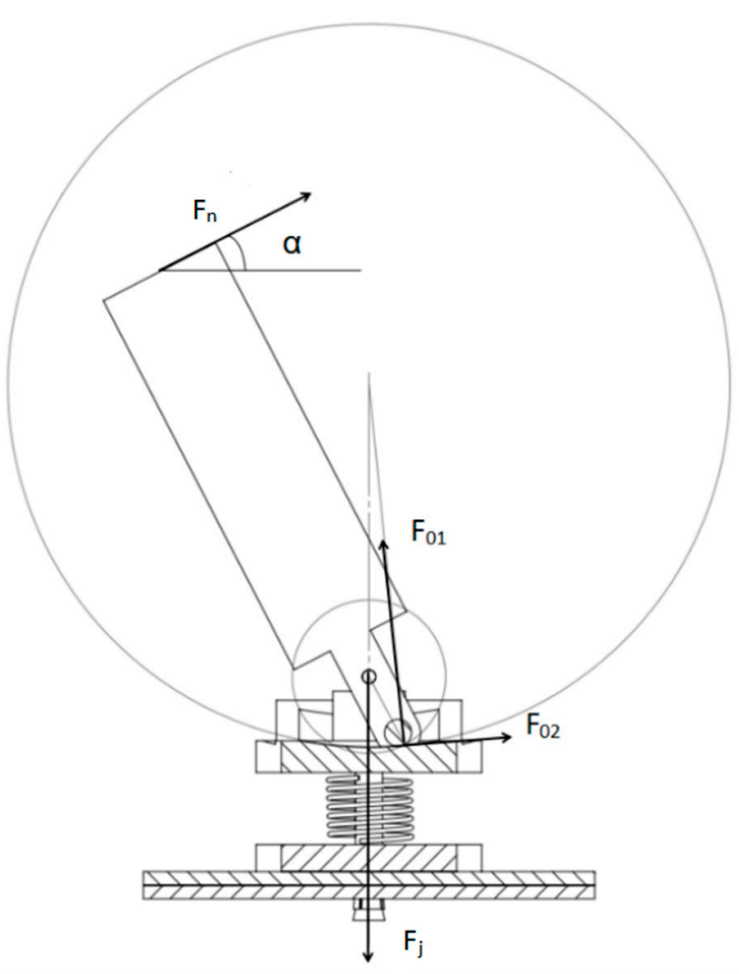

(a)

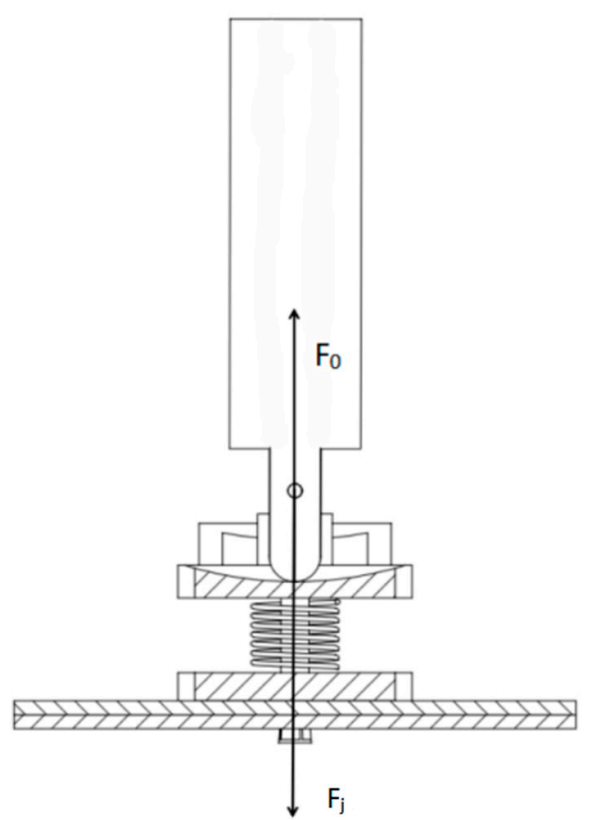

(b)

Figure 4. (a) Force analysis of the clamping process. (b) Balanced state.

Assuming that the contact point between the user and the lever is at the head of the lever, the direction is perpendicular to the lever axis and diagonally upward. The reaction force of the chute table acting on the short part of the lever was decomposed into $F_{01}$ and $F_{02}$. The direction of the $F_{j}$ is vertical downward, and the $F_{j}$ is considered to be the resultant force of the lever from the pin shaft.

The force analysis of the contact point between the bottom of the lever and the chute table is enlarged, as follows:

In Figure 5, $\beta$ can be calculated by the law of cosines:

$$
\beta=\arccos \frac{L_{\mathrm{s}}^{2}+R^{2}-\left(R-L_{s} \cdot \sin \theta-\Delta \mathrm{x}\right)^{2}}{2 \mathrm{~L}_{s} \cdot R}
$$

$\gamma$ is the angle between component force $F_{02}$ and the horizontal line:

$$
\gamma=\frac{\pi}{2}-\theta-\beta=\frac{\pi}{2}-\theta-\arccos \frac{L_{\mathrm{s}}{ }^{2}+R^{2}-\left(R-L_{s} \cdot \sin \theta-\Delta \mathrm{x}\right)^{2}}{2 \mathrm{~L}_{s} \cdot R}
$$

Substitute it into Equation (1), and the difference between the theoretical compression amount and the actual compression amount of the spring $\mathrm{x}_{0}-\mathrm{x}$ is too small to be ignored:

$$
\gamma=\alpha-\arccos \frac{L_{\mathrm{s}}^{2}+R^{2}-\left(R-L_{S} \cdot \cos \alpha\right)^{2}}{2 \mathrm{~L}_{s} \cdot R}
$$




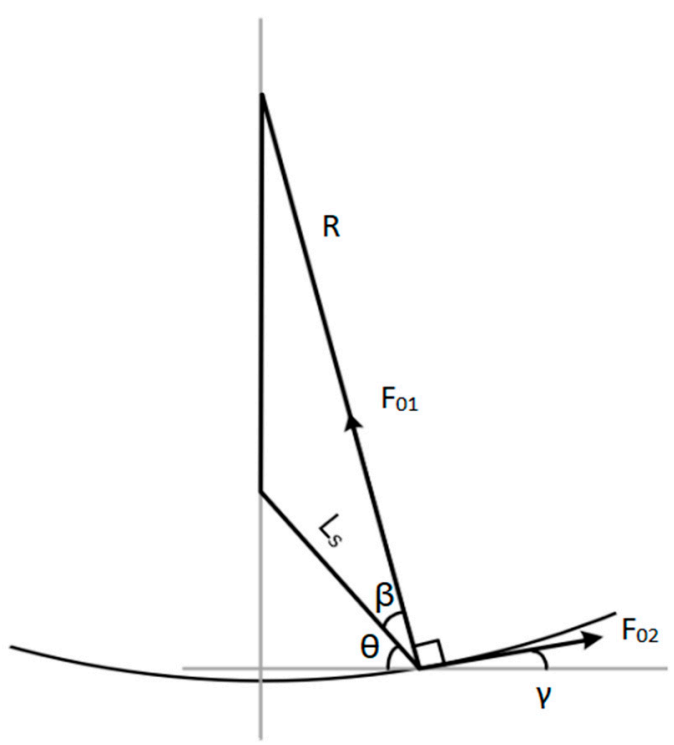

Figure 5. Force decomposition at the bottom of the lever.

2. Force analysis of the device:

To better analyze the force situation, in Figure 5, the reaction force of the chute table acting on the short part of the lever was decomposed into $F_{01}$ and $F_{02}$.

The angle between $F_{01}$ and the horizontal line is the sum of $\theta$ and $\beta$, and the angle between $F_{02}$ and the horizontal line is $\gamma$.

Figure 6 shows the force of the device, from the perspective of the force balance of the device, it can be derived:

$$
\begin{gathered}
F_{01} \cdot \sin \gamma=F_{\mathrm{n}} \cdot \cos \alpha+F_{02} \cos \gamma \\
F_{\mathrm{j}}=F_{01} \cdot \cos \gamma+F_{02} \sin \gamma+F_{\mathrm{n}} \cdot \sin \alpha
\end{gathered}
$$

The moment balance equation of the lever fulcrum is as follows:

$$
F_{\mathrm{n}} \cdot L_{1}=F_{01} \cdot L_{\mathrm{s}} \cdot \sin \beta+F_{02} \cdot L_{\mathrm{s}} \cdot \cos \beta
$$

Simultaneous Equations (9)-(11) obtain the relationship between tightening force and clamping force:

$$
F_{\mathrm{n}}=\sqrt{2} \cdot F_{j} \frac{\sin \left(\beta+\frac{\pi}{4}\right)}{K_{1} \cdot \cos \gamma+\sin \alpha \cdot(\sin \beta+1)+\frac{\cos \alpha}{\tan \gamma}}
$$

where $K_{1}$ represents the length ratio of the long part to the short part of the lever $\frac{L_{1}}{L_{\mathrm{s}}}, \alpha, \beta$, and $\gamma$ can be calculated by Equations (1), (6), and (8), respectively. $F_{j}$ can be calculated by Equation (5).

The amount of tightening force should be taken into account in the design to avoid excessive tightening force. 


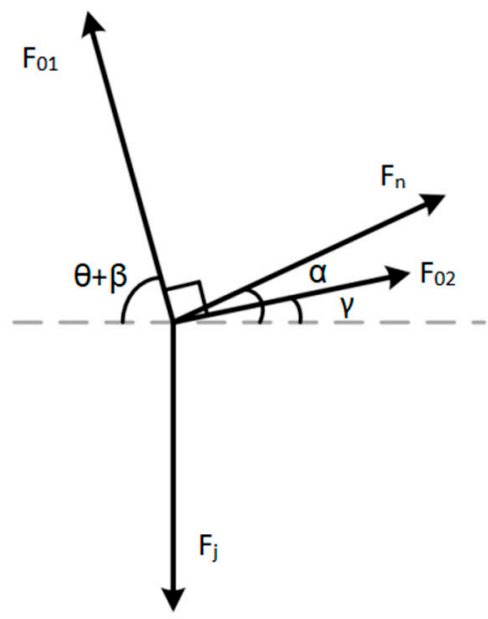

Figure 6. Force on lever.

4. Materials and Methods

4.1. Experimental Procedure

1. An experimental platform was set up, as shown in Figure 7.

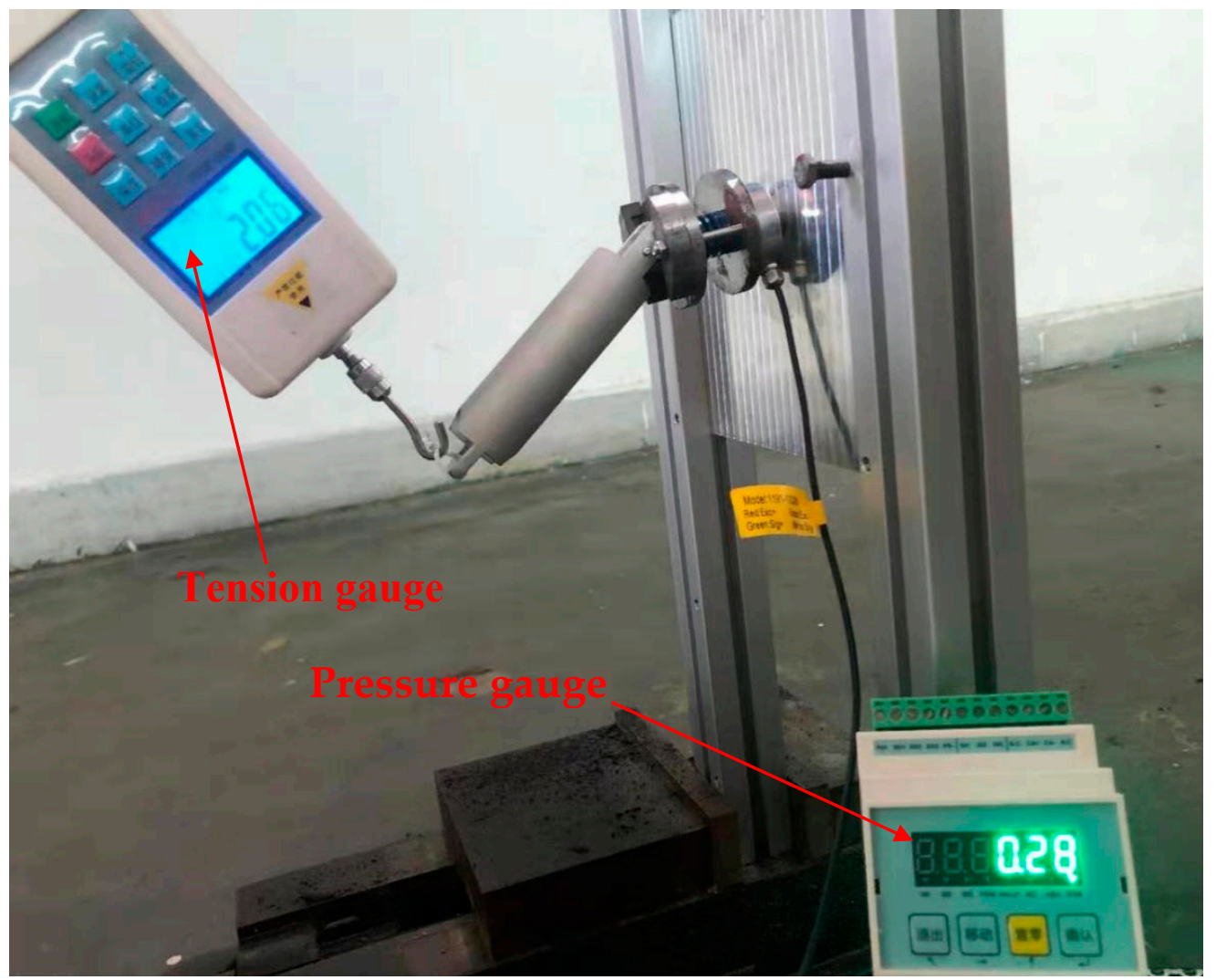

Figure 7. Experimental test platform.

In order to facilitate the force measurement, the experimental device was placed vertically. The base of this device was made of metal, the tension meter produced by Wei Du company was used to measure the force of the lever, and the clamping force between the two plate parts was measured with a pressure meter produced by Arizon company.

2. The pressure gauge and the tension gauge was installed, and the pressure gauge on the experimental platform was fastened with fasteners; 
3. The tension gauge was perpendicular to the lever, and the tension was applied through the tension gauge until the fastener locked the plate parts;

4. The values displayed by the tension gauge and pressure gauge was recorded;

5. The tests were repeated 5 times and an average was calculated;

\subsection{Main Parameters of Parts}

In order to verify the validity of the theoretical method, we assume that the related values of materials and sizes were determined and illustrated in Table 2.

Table 2. Main parameters of parts.

\begin{tabular}{|c|c|c|c|c|c|}
\hline Components & Lever & Chute Table & Spring & $\begin{array}{l}\text { Adjustment } \\
\text { Board }\end{array}$ & Workpiece \\
\hline Material & $\begin{array}{l}\text { aluminum alloy } \\
6061\end{array}$ & 45 steel & $55 \mathrm{SiCr}$ alloy steel & 45 steel & 45 steel \\
\hline \multirow{4}{*}{ Related size } & $\begin{array}{l}\text { total length } \\
133.70 \mathrm{~mm}\end{array}$ & thickness $5.95 \mathrm{~mm}$ & $\begin{array}{l}\text { outer diameter } \\
18 \mathrm{~mm}\end{array}$ & thickness $5.98 \mathrm{~mm}$ & thickness $3.10 \mathrm{~mm}$ \\
\hline & $\begin{array}{l}\text { short handle } \\
\text { length } 19.77 \mathrm{~mm}\end{array}$ & $\begin{array}{l}\text { chute radius } 80.00 \\
\mathrm{~mm}\end{array}$ & $\begin{array}{l}\text { inner diameter } \\
\quad 9 \mathrm{~mm}\end{array}$ & $\begin{array}{c}\text { center aperture } \\
6.93 \mathrm{~mm}\end{array}$ & $\begin{array}{c}\text { center aperture } \\
7.18 \mathrm{~mm}\end{array}$ \\
\hline & $\begin{array}{c}\text { long handle length } \\
113.93 \mathrm{~mm}\end{array}$ & $\begin{array}{l}\text { center aperture } \\
4.94 \mathrm{~mm}\end{array}$ & $\begin{array}{l}\text { free length } \\
20.20 \mathrm{~mm}\end{array}$ & & \\
\hline & & & $\begin{array}{c}\text { compression rate } \\
40 \%\end{array}$ & & \\
\hline
\end{tabular}

\section{Results and Discussion}

\subsection{Theoretical Calculation}

Through the spring compression experiment, the spring coefficient of elasticity was $52.3 \mathrm{~N} / \mathrm{mm}, L_{s}=19.77 \mathrm{~mm}$. At the beginning of the clamping phase, the angle $\theta$ between the lever and the horizontal line was measured to be $45^{\circ}, R=80 \mathrm{~mm}$. The free length of the spring was $20.2 \mathrm{~mm}$, the compressed length was $17.1 \mathrm{~mm}$, and so the compressed amount was $3.1 \mathrm{~mm}$. By substituting the above parameters into Equation (5), and assuming that $\Delta h$ was $0, F_{j}$ was:

$$
F_{j}=\mathrm{k} \cdot\left(\mathrm{x}_{0}+\Delta h\right)=52.3 \times 3.1=162.13 \mathrm{~N}
$$

The tightening force was calculated, and the theoretical clamping force was taken as $162.13 \mathrm{~N}$ and the tightening angle $\alpha$ as $30^{\circ}$. The above parameters were substituted into Equations (6) and (7):

$$
\begin{gathered}
\beta=\arccos \frac{19.77^{2}+80^{2}-\left(80-19.77 \times \cos 30^{\circ}\right)^{2}}{2 \times 19.77 \times 80}=26.37^{\circ} \\
\gamma=\alpha-\beta=30-26.37=3.63^{\circ}
\end{gathered}
$$

The angle $\beta$ and $\gamma$ was $26.37^{\circ}$ and $3.63^{\circ}$, respectively.

By supposing that $K_{1}$ was the ratio of the length of the long part to the short part of the lever, $K_{1}=\frac{L_{l}}{L_{\mathrm{s}}}=\frac{113.93}{19.77}=5.76$. The above parameters were then substituted into Equation (11):

$$
F_{\mathrm{n}}=\sqrt{2} \cdot F_{j} \frac{\sin \left(\beta+\frac{\pi}{4}\right)}{K_{1} \cdot \cos \gamma+\sin \alpha \cdot(\sin \beta+1)+\frac{\cos \alpha}{\tan \gamma}}
$$

The theoretical tightening force was $10.8 \mathrm{~N}$. 


\subsection{Data Comparison}

As the lever was affected by gravity, the device had an initial pulling force during measurement, which is shown in Figure 7 . The measurement results of the tension gauge and pressure gauge are shown in Figure 8:

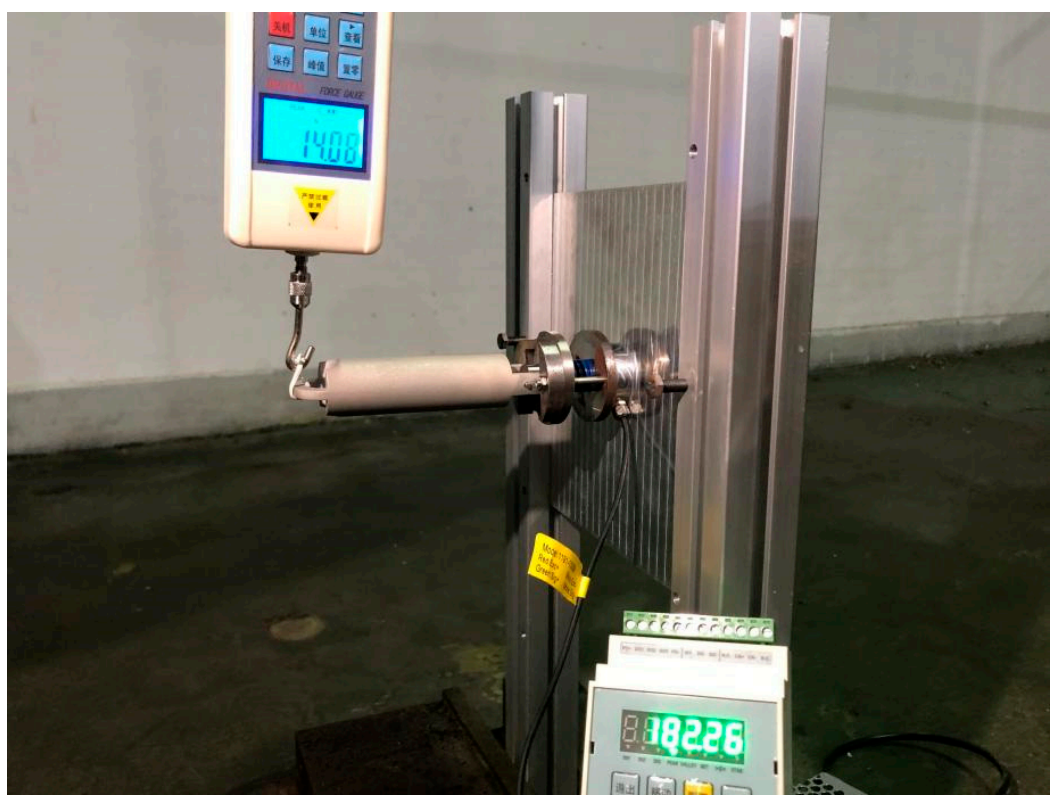

Figure 8. Experimental setup.

The comparison between the theoretical and actual values for the tension and pressure was as follows.

\subsection{Discussion}

It could be found from Table 3 that there was a difference between the theoretical calculation value and the actual value. Because there were errors in the various dimensions of the parts, as well as error values in the instrument measurement process, the errors were accumulated. Besides this, when calculating the theoretical clamping force, we believed that there was no relative displacement between the expansion anchor and the plate. However, in fact, due to the plasticity of the expansion anchor, the expansion anchor was squeezed to produce elasticity reaction force when the pin was pressed down by the lever. This caused an increase in the actual clamping force. Meanwhile, in the analysis, the small gravity of the lever and the friction force between the actual lever and the chute table were ignored, which caused the actual tightening force to be greater than the theoretical tightening force.

Table 3. Comparison of results.

\begin{tabular}{cccc}
\hline & Theoretical Value (N) & Actual Value (N) & Error Rate \\
\hline Pressure & 162.13 & 182.26 & $8.9 \%$ \\
\hline Tension & 10.8 & 14.08 & $7.6 \%$ \\
\hline
\end{tabular}

At the same time, the following three advantages shown in Table 4 of this device can be seen from the experimental process of Figures 7 and 8 . 
Table 4. Advantages of fast temporary fasteners.

\begin{tabular}{ccc}
\hline Rapid Assembly & Labor-Saving & Reversible Ability \\
\hline $\begin{array}{c}\text { The lever mechanism is } \\
\text { can be completed by simply } \\
\text { moving the lever. }\end{array}$ & $\begin{array}{c}\text { The } \\
\text { matched with the expansion } \\
\text { anchechanism to reduce }\end{array}$ & $\begin{array}{c}\text { Adopt the elastic expansion } \\
\text { anchor and spatial cross track } \\
\text { make a reliable } \\
\text { clamping process. }\end{array}$ \\
\hline
\end{tabular}

\section{Conclusions}

To solve the problems of low efficiency and high cost caused by the bilateral installation of the traditional pre-joining process, this paper proposed a new fastener which is suitable for unilateral pre-joining process of the aircraft panels.

In contrast to bolts by bilateral fastening with time-consuming, labor-intensive, and low-efficiency characteristics, the fastener has many advantages: low comprehensive cost, convenient operation, and quick disassembly.

For this fastener, the clamping force was provided by combining it with the lever mechanism, expansion shaft, and clamping spring. Furthermore, the amount of precompression of spring could be adjusted according to the different needs of clamping force. Therefore, it could provide reliable clamping force for pre-joining process. Meanwhile, the fastener combined with lever mechanism could realize the labor-saving in operation. In this fastener, spring was adapted to overcome the tolerance of workpiece, and the reversal function of the device was realized by the elastic expansion anchor and a space cross groove of the chute table.

After the fasteners were applied to the panel assembly process, the results showed that the fasteners could be assembled and disassembled only by rotating back and forth at a small angle with a small force.

In the process of design and experiment, a difference between the theoretical calculation value and the actual value could be found. The theoretical clamping force was $162.13 \mathrm{~N}$, when the actual clamping force was $182.26 \mathrm{~N}$. The error ratio between them was $8.9 \%$, because, when calculating the theoretical clamping force, we ignored the compressibility of expansion anchors that would cause the increasement of the actual clamping force. The theoretical tightening force was $10.8 \mathrm{~N}$, while the actual tightening force was $14.08 \mathrm{~N}$. The error ratio between them was $7.6 \%$, because in the analysis, the small gravity of the lever and the friction force during the tightening process were ignored, which caused the actual tightening force to be greater than the theoretical tightening force.

There are also some disadvantages associated with this fasteners. The elasticity of the expansion anchor could be weakened after used for a several times, which may bring inconvenience in use. When the adjusting spring is employed to adapt the tolerances, the pre-compression amount on the clamping force may hardly change. The above two points could be the direction of further research.

Author Contributions: Conceptualization, W.T. and W.Q.; methodology, W.T.; val-idation, Y.Y.; formal analysis, X.X.; investigation, X.X.; resources, W.T.; data cura-tion, Y.Y.; writing—original draft preparation, X.X.; writing—review and editing, W.T.; visualiza-tion, X.X.; supervision, W.T.; project administration, W.T. and W.Q.; funding acquisition, W.T. All authors have read and agreed to the published version of the manuscript.

Funding: This research was funded by Shaoguan City Science and Technology Planning Project (No. 2019 sn067) and Educational Research Project for Young and Middle-aged Teachers of Fujian Education Department (No. JAT170193).

Conflicts of Interest: The authors declare no conflict of interest. 


\section{References}

1. Liu, J.T.; Zhao, A.; Liu, Y.; Dong, H.Y.; Bi, Y.B. Numerical and experimental investigation on the rivet head flushness in automatic countersunk riveting. Int. J. Adv. Manuf. Technol. 2020, 110, 395-411. [CrossRef]

2. Qu, W.W.; Lu, X.G.; Yang, D. Influence of pre-joining scheme on panel dynamic characteristic. J. Zhejiang Univ. (Eng. Sci.) 2017, 51, 336-343. (In Chinese)

3. Zeba, G.; Dabić, M.; Čičak, M.; Daim, T.; Yalcin, H. Technology mining: Artificial intelligence in manufacturing. Technol. Forecast. Soc. Change 2021, 171, 120971. [CrossRef]

4. Xie, Y. The "Intelligent Revolution" Transcends the "Industrial Revolution". Inf. China 2019, 12, 43-46. (In Chinese)

5. Yang, Q.H. Promote industrial upgrading with smart manufacturing as the starting point. Macroecon. Manag. 2021, 3, 78-90. (In Chinese)

6. Liu, Y. Thoughts and Suggestions on the Development Strategy of China's Manufacturing Supply Chain. Sci. Technol. China 2020, 9, 8-12. (In Chinese)

7. Qi, Z.C.; Wang, M.; Cheng, W.L.; Wang, W. Optimization of Pre-Tightening Arrangement for One-Side Pressed Hole Making Between Aircraft Frames. Aeronaut. Manuf. Technol. 2019, 62, 58-63. (In Chinese)

8. Yang, D.; Qu, W.W.; Ke, Y.L. Evaluation of residual clearance after pre-joining and pre-joining scheme optimization in aircraft panel assembly. Assem. Autom. 2016, 36, 376-387. [CrossRef]

9. Gang, L.; Tang, W.; Ke, Y.L.; Chen, Q.L.; Bi, Y.B. Modeling of fast pre-joining processes optimization for skin-stringer panels. Assem. Autom. 2014, 34, 323-332.

10. Gang, L.; Tang, W.; Ke, Y.L.; Chen, Q.L.; Chen, X.M. Pre-joining process planning model for a batch of skin-stringer panels based on statistical clearances. Int. J. Adv. Manuf. Technol. 2015, 78, 41-51.

11. Qu, W.W.; Tang, W.; Ke, Y.L. Pre-joining processes optimization method for panel orienting to the clearances suppression of units and the clearances flow among units. Int. J. Adv. Manuf. Technol. 2018, 94, 1357-1371. [CrossRef]

12. Zhou, S.Y.; Han, Z.R.; Guo, X.F.; Liang, W.X. Application of Simulated Annealing Algorithm in Arrangement of Pre-connected Hole. Mech. Sci. Technol. Aerosp. Eng. 2019, 38, 959-962. (In Chinese)

13. Liu, X.; An, L.L.; Wang, Z.G.; Tan, C.B.; Wang, X.P.; Yu, S.X. Assembly Variation Analysis of Aircraft Panels under Part-to-part Locating Scheme. Int. J. Aerosp. Eng. 2019, 2019, 19-128-20191016. [CrossRef]

14. Huang, X.D.; Wang, Q. Desing of end effector for pre-connected fasteners automatic installation in aircraft assembly. Manuf. Technol. Mach. Tool 2017, 9, 17-20. (In Chinese)

15. Cheng, Y.L.; Mei, Q.Y. Research of Rapid Assembly Approach for Fasteners Based on Feature Recognition. Electro-Mech. Eng. 2016, 32, 42-45. (In Chinese)

16. Camacho, J.; Veiga, F.; Penalva, M.L.; Diez-Olivan, A.; Deitert, L.; López de Lacalle, N. On-Line Monitoring of Blind Fastener Installation Process. Materials 2019, 12, 1157. [CrossRef] [PubMed]

17. Wilson, W.C.; Rogge, M.D.; Fisher, B.H.; Malocha, D.C.; Atkinson, G.M. Fastener Failure Detection Using a Surface Acoustic Wave Strain Sensor. IEEE Sens. J. 2012, 12, 1993-2000. [CrossRef]

18. Li, Y.; Cao, J.B.; Li, X.L. Optimization Design of Patch Shape for Rivet Repair of Aircraft Skin. Intell. Syst. Appl. Mater. 2012, 466, 1000-1005. [CrossRef]

19. Jiang, C.J.; Sun, J.H.; Li, L. The Influence of Assembly design of Automobile Parts on Assembly Efficiency. Technol. Innov. Manag. 2017, 38, 383-388. (In Chinese) 